\title{
HETEROGENIZATION OF HOMOGENEOUS PERFLUOROTHIOPHENE Rh(I) COMPLEX AND EXAMINATION OF HYDROGENATION ACTIVITY IN SCCO $\mathrm{SEDIA}_{2}$
}

\author{
Filiz YILMAZ ${ }^{1, *}$, Yusuf KARAAĞAÇ, İbrahim KANİ ${ }^{1}$ \\ ${ }^{1}$ Department of Chemistry, Faculty of Science, Anadolu University, Eskişehir, Türkiye
}

\begin{abstract}
Rhodium(I) complex of perfluorinated thiophene ligand was synthesized and heterogenized over the modified silica support. SEM, XRF, TGA and BET methods were used for the characterization of the heterogenized catalyst (SiAPTES-RhL). Heterogenization of catalyst and the catalytic activity tests were carried out in $\mathrm{scCO}_{2}$ as a greener alternative to traditional reaction media. The catalytic activities of complex were investigated in hydrogenation reactions of some alkenes such as styrene, 1-octene and cyclohexene. 100\% ethyl benzene conversion was observed at $370 \mathrm{~K}, 10 \mathrm{bar} \mathrm{H}_{2}$ and 1900 psi total pressure in styrene hydrogenation. Also, it was found that the catalyst remains active at least throughout ten cycles. Similarly, the activity of the catalyst in the hydrogenation of 1-octene and cyclohexene was investigated. For 1-octene, 100\% n-octan selectivity was obtained at $370 \mathrm{~K}$ and $10 \mathrm{Bar} \mathrm{H}_{2}$. The catalyst was found to be effective at $370 \mathrm{~K}$ while the activity was low at 350 and $360 \mathrm{~K}$ in cyclohexen hydrogenation. When compared with the homogenous system, the heterogenized catalyst had more activity and selectivity and also reusability without losing its activity.
\end{abstract}

Keywords: Heterogenized homogeneous catalyst, Silica support rhodium complex, $\mathrm{scCO}_{2}$, Hydrogenation

\section{INTRODUCTION}

Transition metal complexes used in scientific and industrial research are usually dissolved in harmful organic solvents [1]. One of the most important goals of green chemistry is to reduce use of these toxic solvents. Supercritical fluids (SCFs) have frequently been used as an environmentally friendly alternative to conventional organic solvents in recent years. Supercritical fluids have significant advantages as reaction medium [2-4]. Their physico-chemical properties such as density, dielectric constant, viscosity and permeability can be adjusted by changing the temperature and pressure. Mass transfer is quite fast. SCFs mix very well with the gas reactant such as hydrogen and oxygen. Also, they can be easily removed from the reaction products [5]. Supercritical carbon dioxide $\left(\mathrm{scCO}_{2}\right)$ with low critical pressure $(72.8 \mathrm{~atm})$ and temperature $\left(31.1^{\circ} \mathrm{C}\right)$ is the most popular $\mathrm{SCF} . \mathrm{scCO}_{2}$ is inexpensive, non-flammable, non-toxic and inert gas [6] $\mathrm{scCO}_{2}$ can easily be removed from products and catalysts through depressurization or through changing the temperature [7-9]. $\mathrm{ScCO}_{2}$ is used in many different applications such as extraction, dry cleaning, decaffeination of coffee and polymerization reactions. $\mathrm{scCO}_{2}$ can also be used as alternative solvent in homogeneous and heterogeneous catalysis. Although homogeneous catalysis has such advantages over heterogeneous ones as selectivity and effectivity, the major disadvantages in homogeneous catalysis include difficult separation of the catalyst from the products and recovery-reuse of expensive catalysts [10-13]. Heterogenization of homogeneous catalysts on the inorganic support materials helps solve this problem $[14,15]$.

In this study, we tried to hydrogenate some olefins in supercritical carbon dioxide $\left(\mathrm{scCO}_{2}\right)$. For this purpose, we synthesized silica-supported perfluoroalkylated thiophene $\mathrm{Rh}(\mathrm{I})$ complex (SiThioRh) to use it as heterogenized catalyst. The structure of ligand (perfluoroalkylated thiophene) was modified with perfluorinated carbon chain to increase the interaction of the catalyst with $\mathrm{scCO}_{2}$. Homogeneous catalyst (ThioRh) was prepared through complexation of ligand with $\mathrm{Rh}(\mathrm{I})$ metal ion, and then it was immobilized to the silica support for heterogenization. Before heterogenization of homogeneous catalyst

*Corresponding Author: fyilmaz@anadolu.edu.tr 
on the surface of the solid support, it is necessary to modify the support surface $[15,16]$. The most common method for the the modification of the silica surface is the reaction of silica gel with 3aminopropyltriethoxysilane (APTES), which carries terminal amine groups $\left(-\mathrm{NH}_{2}\right)$. The reaction of $\mathrm{NH}_{2}$ groups with functional groups present in the homogeneous catalyst allows covalent attachment of the catalyst to the silica material [17]. Heterogenization of homogeneous catalyst was carried out in $\mathrm{scCO}_{2}$ media. Thus, the advantages of heterogenized homogeneous catalytic systems and supercritical fluids were gathered. The activity of heterogenized catalyst was tested in the hydrogenation reactions of styrene, 1-octene and cyclohexene in $\mathrm{scCO}_{2}$ media. The effects of $\mathrm{H}_{2}$ pressure, temperature, substrat/catalyst ratio and total pressure on the catalytic activity of complex were determined. Reusability of catalyst in styrene hydrogenation was investigated as well.

\section{EXPERIMENT}

All the chemicals used were of analytical grade. Thiophene-2-carbonyl chloride (Aldrich), $1 \mathrm{H}, 1 \mathrm{H}$ perfluoro-1-nonanol (Aldrich), chloro (1,5-cyclooctadiene) rhodium (I) dimer (Aldrich), triethylamine (Merck), styrene (Fluka), cyclohexane (Fluka), 1-octene (Merck), silica gel (Merck), APTES (3Aminopropyl triethoxysilane) (Aldrich) were used without any further purification. The organic solvents were used after purification. All of the traditional synthesis were carried out under nitrogen atmosphere using standard schlenk techniques. $100 \mathrm{~mL}$ stainless steel high pressure reactor (Parr inst.) which contained a magnetic bar and a temperature controller was used at the catalytic reactions. Elementar Vario EL III microanalyzer device was used for Elemental analysis. FT-IR spectra were recorded between 400 and $4000 \mathrm{~cm}^{-1}$ using a Perkin Elmer Spectrum 100 Spectrometer. The samples were incorporated with $\mathrm{KBr}$ and pressed into a pellet. ${ }^{1} \mathrm{H}-\mathrm{NMR}$ and ${ }^{13} \mathrm{C}-\mathrm{NMR}$ spectra were measured on a Bruker $(500 \mathrm{MHz})$ DPX FT spectrometer using TMS as the internal standard. Thermogravimetric/differential thermal analyses were performed on a Perkin Elmer Diamond TG/DTA instrument. A scanning electron microscope (Carl Zeiss Ultra Plus FESEM SEM) was used to observe the morphology of heterogenized catalyst. Surface area analysis was performed on a Quantachrome Nova 2200e BET instrument. The product distributions in the catalytic experiments were determined by Thermo Finnigan Trace GC including FID detector and Permabond column (SE-54-DF-0.25, $25 \mathrm{~m}$ x $0.32 \mathrm{~mm}$ i.d.).

\subsection{Preparation of Homogeneous Catalyst (ThioRh)}

$\mathrm{Rh}_{2} \mathrm{Cl}_{2}(\mathrm{COD})_{2}$ dimer $(0.0146 \mathrm{~g}, 0.029 \mathrm{mmol})$ was dissolved in $\mathrm{CH}_{2} \mathrm{Cl}_{2}(10 \mathrm{~mL})$ and added to the solution of ligand $(0.1 \mathrm{~g}, 0.18 \mathrm{mmol})$ in the nitrogen atmosphere. The reaction mixture was stirred at room temperature for $6 \mathrm{~h}$. Solvent was removed with rotary evaporator. The slightly beige solid was washed with ether and dried in vacuum (Dec. point $>220^{\circ} \mathrm{C}$, Yield 55\% (0.107 g).

\subsection{Preparation of $-\mathrm{NH}_{2}$ Modified Silica (Si-APTES)}

$2.5 \mathrm{~mL}$ APTES was added slowly under an $\mathrm{N}_{2}$ atmosphere at room temperature to a suspension of 3.15 $\mathrm{g}$ of $\mathrm{SiO}_{2}$ in $250 \mathrm{~mL}$ dry toluene. After complete addition of APTES, the mixture was refluxed at $80{ }^{\circ} \mathrm{C}$ for $24 \mathrm{~h}$ in $\mathrm{N}_{2}$ atmosphere. The product was filtered and washed with dry toluene followed by methanol. The solid was washed with $250 \mathrm{~mL}$ dichloromethane via Soxhlet extractor.

\subsection{Preparation of Heterogenized Homogeneous Catalyst (Si-APTES-ThioRh)}

$300 \mathrm{mg}$ amino-functionalized silica (Si-APTES) and $20 \mathrm{mg}$ ThioRh complex were placed into a $25 \mathrm{~mL}$ Tharr high-pressure stainless steel reactor with two sapphire windows to see the inner part of the reactor. The vessel was closed and mixed under $1500 \mathrm{psi} \mathrm{CO}_{2}$ pressure at $70{ }^{\circ} \mathrm{C}$ temperature for $2 \mathrm{~h}$. After the reaction, the vessel was cooled and $\mathrm{CO}_{2}$ was carefully removed from the reactor. Si-APTES-ThioRh catalyst was filtered and then washed with dry acetone followed by methanol. The reaction procedure and the possible structure of the catalyst are given in Figure 1. 


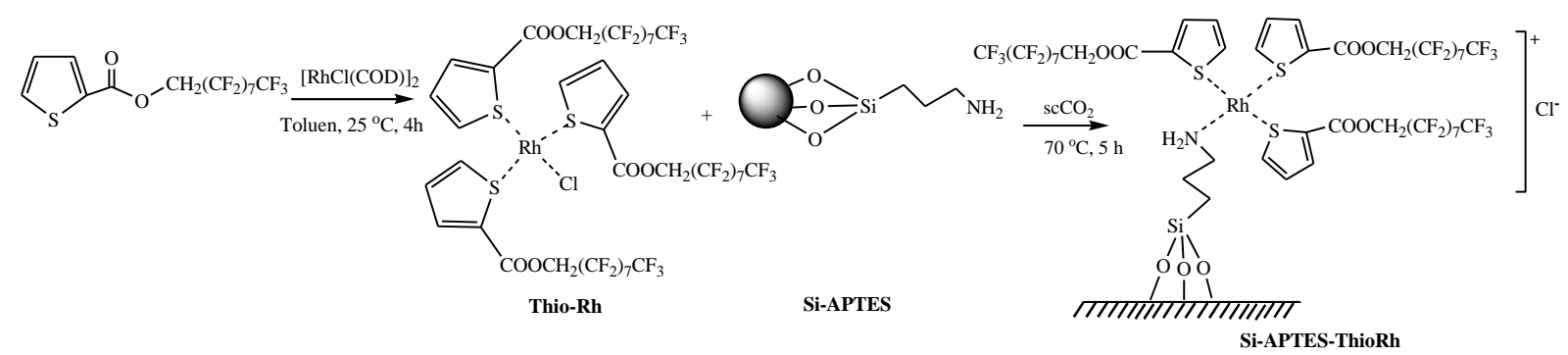

Figure 1. Preperation of the heterogenized homogeneous catalyst (Si-APTES-ThioRh)

\subsection{Hydrogenation Reaction of Olefins in $\mathrm{scCO}_{2}$}

The catalytic hydrogenation of olefins in $\mathrm{scCO}_{2}$ media was performed in $100 \mathrm{~mL}$ high pressure reactor of Parr. A certain amount of substrat and catalyst was charged into the reactor. The reactor was then sealed and flushed three times with $\mathrm{CO}_{2}$ at 5 bar. The $\mathrm{H}_{2}$ gas was introduced at room temperature in the reactor and the reactor was heated to the set temperature. $\mathrm{CO}_{2}$ was introduced into the reactor using a high pressure syringe pump (Isco Inc. Model 260D). Samples were taken at timed intervals in a cooled hexane and analyzed with GC.

\section{RESULTS}

\section{1. Characterization}

The synthesis and characterization of o- $\mathrm{COOCH}_{2}\left(\mathrm{CF}_{2}\right)_{7} \mathrm{CF}_{3} \mathrm{SC}_{4} \mathrm{H}_{3}$ using as a ligand was reported by the researchers of the present study previously [18]. In this study, silica-supported rhodium complex of this ligand was prepared, and its catalytic activity was investigated in $\mathrm{scCO}_{2}$. In the FTIR spectra of ligand, $\mathrm{C}=\mathrm{O}$ stretching vibration was observed at $1731 \mathrm{~cm}^{-1}$. Also, the sharp peaks at around $1243-1149 \mathrm{~cm}^{-1}$ can be attributed to $\mathrm{C}-\mathrm{F}$ group stretches. The stretching vibrations of $\mathrm{C}-\mathrm{H}$ and $\mathrm{C}=\mathrm{C}$ groups in the thiophene ring were observed at about $3106 \mathrm{~cm}^{-1}$ and $1525-1419 \mathrm{~cm}^{-1}$, respectively. The peaks observed at 968,860 and $585 \mathrm{~cm}^{-1}$ belong to the $\mathrm{C}(\operatorname{aryl})-\mathrm{S}$ bond vibrations. The C-S stretching peak at $585 \mathrm{~cm}^{-1}$ shifted to $559 \mathrm{~cm}^{-1}$ after the ligand coordinated to the metal centre. The weak band at $471.68 \mathrm{~cm}^{-1}$ in spectra of the rhodium complex was related to the stretching frequencies of the $\mathrm{v}(\mathrm{Rh}-\mathrm{S})$ bond, which indicates that the ligand coordinated to the $\mathrm{Rh}^{+}$ion through the sulfur atom of thiophene ring. In addition, $\mathrm{v}(\mathrm{Rh}-\mathrm{Cl})$ stretching vibration shifted from $280.7 \mathrm{~cm}^{-1}$ to $293.42 \mathrm{~cm}^{-1}$ in Far-IR spectra (See supplementary Figure 6). The chlorine atom has higher electronegativity and attracts electrons from the metal. This causes the Rh-Cl bond strength to increase and the frequency to shift upwards. After the homogeneous catalyst was heterogenized on modified silica support, the antisymmetric and symmetric stretching vibration bands of Si-O-Si bonds were observed at around $1095 \mathrm{~cm}^{-1}$ and $800 \mathrm{~cm}^{-1}$, respectively [19]. The $\mathrm{v}\left(\mathrm{C}(\right.$ aryl)-S $)$ stretching peak at $970 \mathrm{~cm}^{-1}$ indicates that the complex is immobilized to the silica (See supplementary Figure 8).

The surface area and morphological analysis of the heterogenized complex were determined with BET and SEM techniques, and its structural composition was examined with XRF analysis and thermal analysis. The BET surface area of the unmodified silica was found to be $425 \mathrm{~m}^{2} / \mathrm{g}$. The surface area of Si-APTES decreased to $258 \mathrm{~m}^{2} / \mathrm{g}$ due to the addition of aminopropyl groups. In addition, a decrease in the surface area after immobilization of rhodium complex was observed (to $182 \mathrm{~m}^{2} / \mathrm{g}$ after immobilization).

The morphologies of silica and heterogenized Rh complex were investigated with the scanning electron microscopy. The images are shown in Figure 2. The morphological changes on the surface of the silica 
matrix occurred after loading the metal complex. The image of the heterogenized Rh complex depicts some assemblages containing aggregates on the silica surface. On the other hand, the complex at the silica surface was not distributed uniformly.

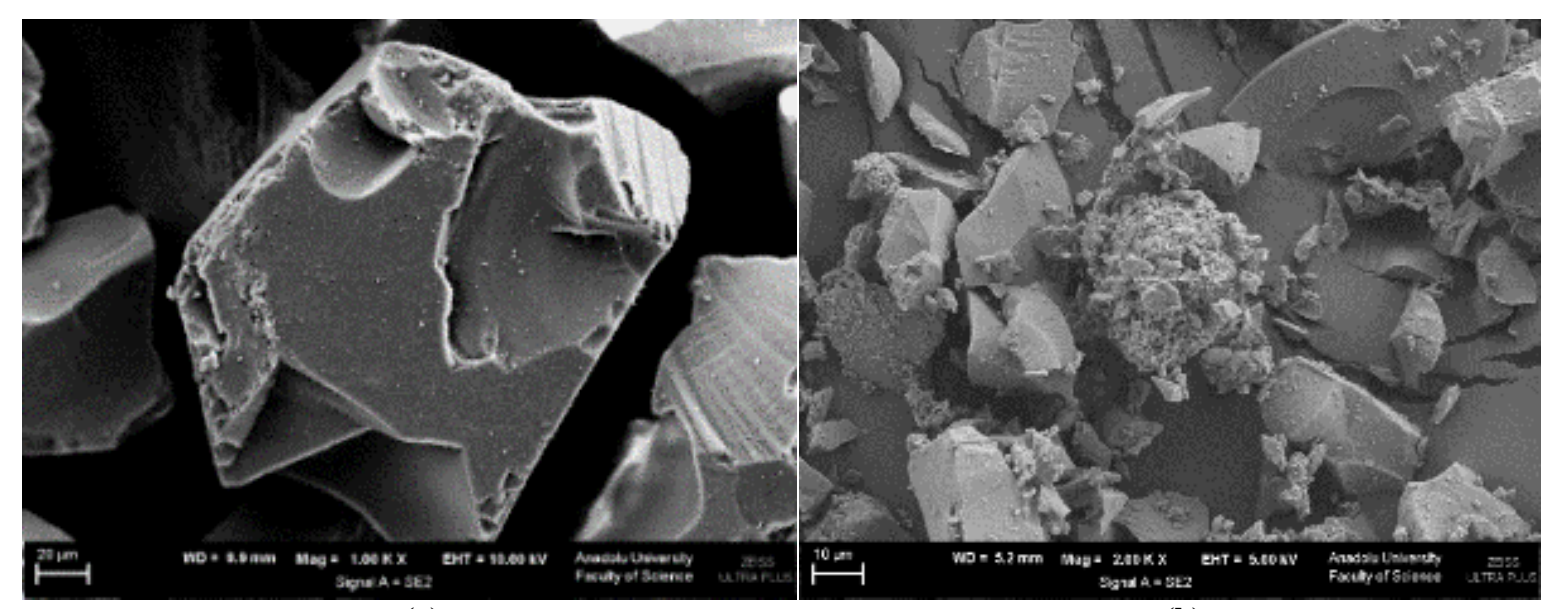

(a)

(b)

Figure 2. (a) SEM images of silica (b) SEM image of Si-APTES-ThioRh catalyst

The simultaneous TG/DTG-DTA technique was used to determine the thermal degradation of the catalyst. Analysis was carried out with the heating rate of $10{ }^{\circ} \mathrm{C} / \mathrm{min}$ in the temperature range of 30$1000^{\circ} \mathrm{C}$ in a nitrogen atmosphere. In the first stage of the analysis, physically adsorbed water molecule was lost at $35-100{ }^{\circ} \mathrm{C}$. The second stage involved decomposition of organic moiety bonded to silica support $\left(212-255^{\circ} \mathrm{C}\right)$. The exothermic peaks at higher temperatures $\left(401-1000{ }^{\circ} \mathrm{C}\right)$ represented the removal of metal and silanol part from the catalyst precursor.

As a result of XRF analysis, $52.25 \% \mathrm{C}, 45.40 \% \mathrm{Si}, 1.1 \% \mathrm{Cl}, 0.25 \% \mathrm{~S}$ and $0.6 \% \mathrm{Rh}$ were found in the 5 mg sample. The results demonstrated that the homogeneous catalyst was immobilized to the modified silica support. The structure of the heterojenized catalyst proposed as a result of the characterization studies is given in Figure 1.

\subsection{Catalytic Reactions}

The catalytic activity of the complex in hydrogenation reactions was investigated for a variety of substrates including aromatic olefin (styrene), lineer olefin (1-octene) and cyclic olefin (cyclohexen). Firstly, we tested the hydrogenation activity of the complex in the styren hydrogenation reaction. The hydrogenation product of styrene is ethyl benzene. The influence of temperature on the catalytic activity of the complex was examined at a temperature ranging from 330 to $370 \mathrm{~K}$ at constant pressures of $\mathrm{CO}_{2}$ and $\mathrm{H}_{2}, 1500$ psi and 10 bar, respectively (Entry 1-5). The results can be seen in Table 1. As shown in Figure 3, temperature exhibits a positive effect on the conversion of ethyl benzene. The TOF value was 247 at $330 \mathrm{~K}$ in $360 \mathrm{~min}$. When the temperature was gradually increased, the TOF value increased steadily. The highest TOF value was obtained as 1488 (99.7\% ethyl benzene) at $370 \mathrm{~K}$. For this reason, the temperature remained constant at $370 \mathrm{~K}$ while examining the effects of other reaction parameters on the catalytic reaction. 


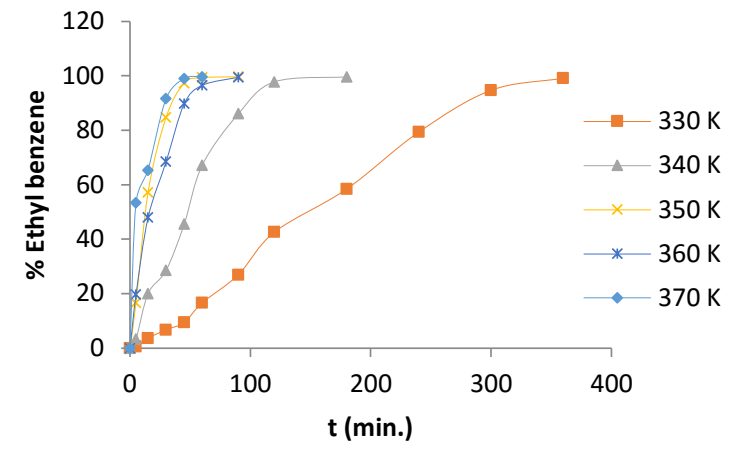

Figure 3. The effect of temperature on styrene hydrogenation

Table 1. Styren hydrogenation with Si-APTES-ThioRh catalyst

\begin{tabular}{|c|c|c|c|c|c|c|c|c|}
\hline & $\begin{array}{c}\mathbf{T} \\
(\mathbf{K})\end{array}$ & $\begin{array}{c}\mathbf{P H}_{\mathrm{H} 2} \\
\text { (bar) }\end{array}$ & $\begin{array}{l}\text { Ptotal } \\
\text { (psi) }\end{array}$ & $\begin{array}{c}\mathbf{V}_{\text {substrat }} \\
(\mu \mathbf{L})\end{array}$ & $\begin{array}{c}\mathrm{t} \\
\text { (min.) }\end{array}$ & $\begin{array}{c}\text { Conversion } \\
(\%)\end{array}$ & TON $^{a}$ & $\begin{array}{l}\text { TOF } \\
\left(h^{-1}\right)\end{array}$ \\
\hline 1 & 330 & 10 & 1500 & 100 & 360 & 99.2 & 1480 & 247 \\
\hline 2 & 340 & 10 & 1500 & 100 & 180 & 99.5 & 1485 & 495 \\
\hline 3 & 350 & 10 & 1500 & 100 & 90 & 99.6 & 1486 & 991 \\
\hline 4 & 360 & 10 & 1500 & 100 & 90 & 99.5 & 1485 & 990 \\
\hline 5 & 370 & 10 & 1500 & 100 & 60 & 99.7 & 1488 & 1488 \\
\hline 6 & 370 & 5 & 1500 & 100 & 360 & 81.0 & 1209 & 201 \\
\hline 7 & 370 & 15 & 1500 & 100 & 90 & 98.6 & 1471 & 981 \\
\hline 8 & 370 & 20 & 1500 & 100 & 90 & 99.4 & 1483 & 989 \\
\hline 9 & 370 & 10 & 1500 & 300 & 180 & 99.3 & 1482 & 494 \\
\hline 10 & 370 & 10 & 1500 & 500 & 360 & 87.7 & 1308 & 218 \\
\hline 11 & 370 & 10 & 1500 & 700 & 360 & 74.3 & 1109 & 185 \\
\hline 12 & 370 & 10 & 1500 & 100 & 45 & 99.0 & 1477 & 1969 \\
\hline 13 & 370 & 10 & 1700 & 100 & 45 & 99.6 & 1486 & 1981 \\
\hline 14 & 370 & 10 & 1900 & 100 & 45 & 100 & 1492 & 1989 \\
\hline
\end{tabular}

${ }^{a} \mathrm{TON}=$ Moles of Products $/$ Moles of Catalyst, ${ }^{b} \mathrm{TOF}=\mathrm{TON} /$ time

In order to determine the effect of $\mathrm{H}_{2}$ pressure on the hydrogenation of styrene, experiments were performed at four different $\mathrm{H}_{2}$ pressures between 5-20 bar (Entry 5-8). There was almost a five-times increase in the TOF value when the pressure increased from 5 bar to 10 bar. As shown in Figure 4, the conversion of ethyl benzene was almost $100 \%$ at the pressure values of 10,15 and 20 bar. As the highest TOF value (1488) was obtained at $10 \mathrm{Bar}_{2}$, the other reaction parameters were investigated under this pressure. 


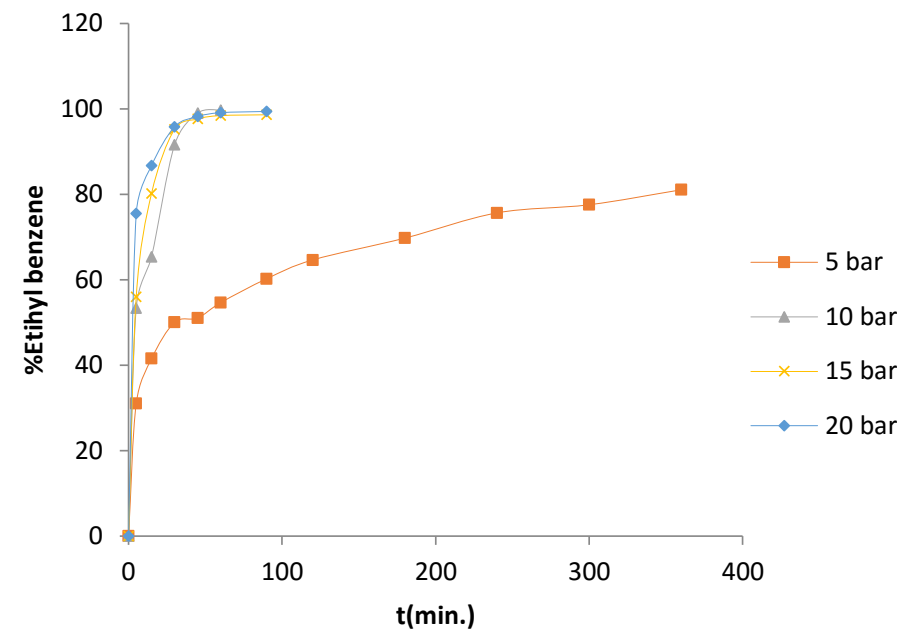

Figure 4. The effect of $\mathrm{H}_{2}$ pressure on styrene hydrogenation

For the purpose of investigating the effect of the substrate amount on the performance of the catalyst, we used three different substrat volumes $(100-700 \mu \mathrm{L})$ at $370 \mathrm{~K}$ and $10 \mathrm{bar}_{2}$ pressure (Experiments 5, 9-11). As the substrate volume increases, the amount of catalyst becomes insufficient compared to the substrate molecules increasing in the medium, so the conversion is reduced. The lowest conversion value (44.3\%) was obtained with $700 \mu \mathrm{L}$ substrate volume (Figure 5).

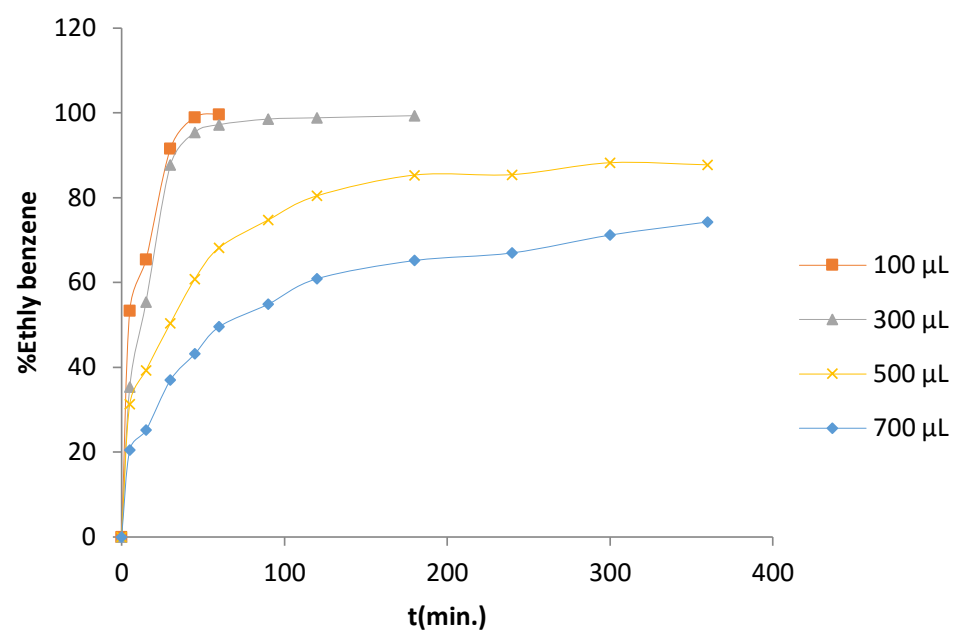

Figure 5. The effect of substrat amount on styrene hydrogenation

The effect of the total reaction pressure on the activity of the catalyst were investigated by changing the total pressure between 1500 and 1900 psi when the other reaction parameters remained constant. As shown in Figure 6, increasing the pressure did not have a considerable effect on the catalytic reaction. The TOF values at all the three pressures were close to each other (Entry 12-14). After the 45-minute reaction, the conversion of ethyl benzene reached $100 \%$ at 1900 psi. 


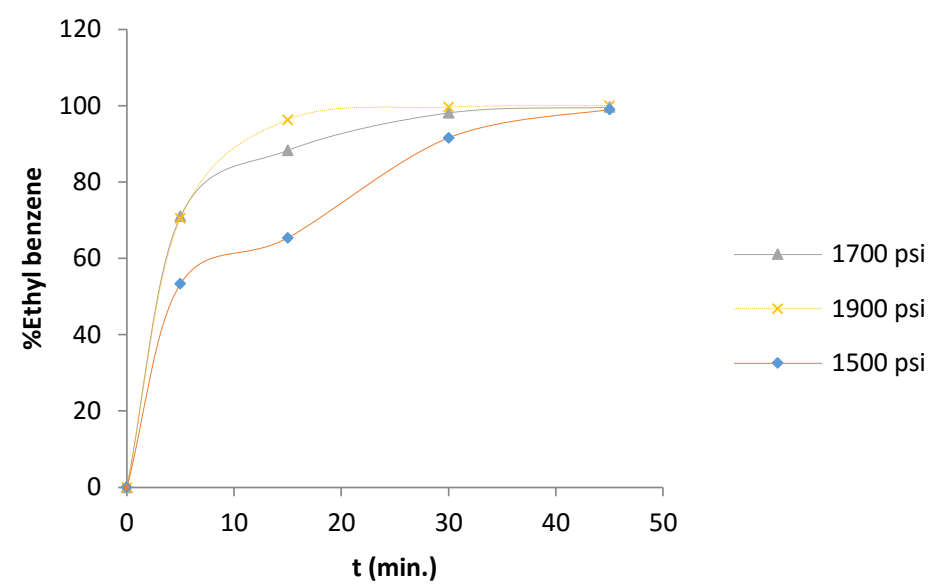

Figure 6. The effect of total pressure on styrene hydrogenation

The main advantage of heterogenized catalysts is their recycling and reusability. For this reason, we tested the reusability of the catalyst for ten cycles at $370 \mathrm{~K}$ and $10 \mathrm{bar}_{2}$ pressure for $1 \mathrm{~h}$. At the end of the hydrogenation reaction, $\mathrm{CO}_{2}$ gas was evacuated from the reactor, and the catalyst was washed with methanol and acetone to remove the substrate and product(s) residues. After the catalyst was dried under vacuum, fresh substrate and catalyst were added into the reactor to operate the next cycle. It was observed that the activity of the catalyst did not change significantly in the first three cycles (Figure7). After the third cycle, its activity started to decrease due to the loss of catalyst from one cycle to the next. The conversion dropped to $86.7 \%$ in the tenth cycle. Loss of activity observed after ten cycle is probably owed to poisoning of the metal centre by decomposition or dimerization. Leaching of the metal may also be a problem if the complex is not strong enough. All these reasons can be cause decrasing catalytic activity.

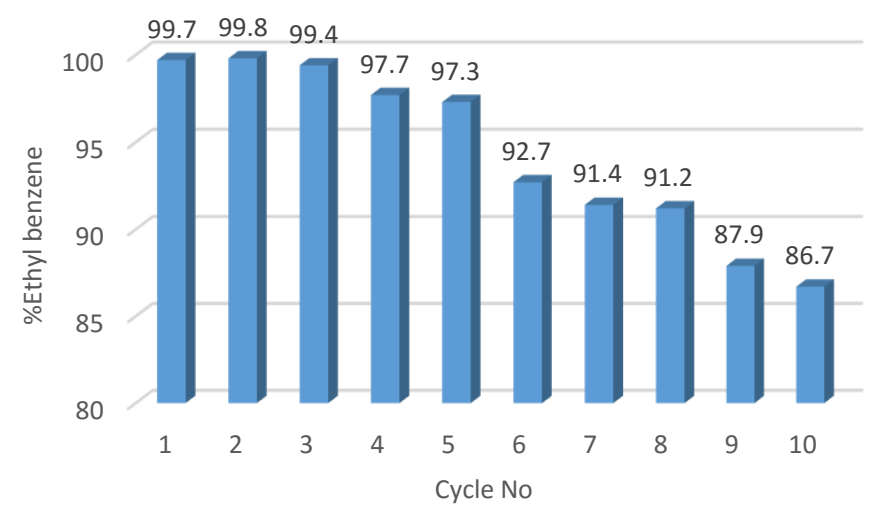

Figure 7. Recycle of catalyst

In order to evaluate the activity of the rhodium complex in 1-octene hydrogenation, catalytic experiments were carried out at temperatures ranging from 323 to $383 \mathrm{~K}$ (Table 2, Entries 1-7) The main hydrogenation product of 1-octene is n-octane, but some other isomerization products can be observed during the hydrogenation reaction. It was found that the TOF value was very low at $330 \mathrm{~K}$. In line with the increasing temperature, the conversion increased as well, and the TOF value reached to 773 at $370 \mathrm{~K}$. Also, the highest selectivity of $100 \%$ was achieved at $370 \mathrm{~K}$. As shown in Figure 8, the temperature has a positive effect on the catalyst activity in the octene hydrogenation. 
Table 2. 1-octene hydrogenation with Si-APTES-ThioRh catalyst

\begin{tabular}{|c|c|c|c|c|c|}
\hline \multicolumn{2}{|c|}{ 1-octene } & \multicolumn{2}{|c|}{$n$-octane } & & \\
\hline $\mathbf{T}(\mathbf{K})$ & $t$ (min.) & $\begin{array}{c}\text { Total conversion } \\
(\%)\end{array}$ & $\begin{array}{c}\text { Product } \\
\text { distribution } \\
(\%)\end{array}$ & TON $^{a}$ & $\begin{array}{l}\text { TOF } \\
\left(\mathbf{h}^{-1}\right)\end{array}$ \\
\hline 330 & 360 & 5.84 & $2.5^{\mathrm{a}}, 2.2^{\mathrm{b}}, 1.1^{\mathrm{c}}$ & 64 & 11 \\
\hline 340 & 360 & 26.65 & $13.6^{\mathrm{a}}, 8.3^{\mathrm{b}}, 4.8^{\mathrm{c}}$ & 293 & 49 \\
\hline 350 & 180 & 99.7 & $75.0^{\mathrm{a}}, 18.7^{\mathrm{b}}, 5.9^{\mathrm{c}}$ & 1097 & 366 \\
\hline 360 & 180 & 100.0 & $89.0^{\mathrm{a}}, 7.9^{\mathrm{b}}, 3.0^{\mathrm{c}}$ & 1100 & 367 \\
\hline 370 & 90 & 100.0 & $100.0^{\mathrm{a}}$ & 1100 & 773 \\
\hline
\end{tabular}

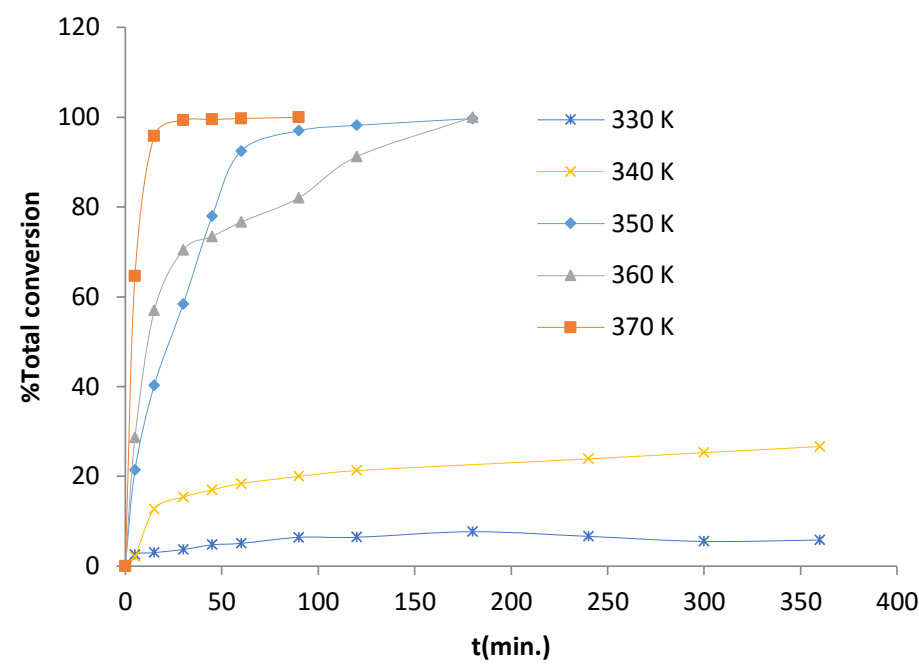

Figure 8. Temperature effect on 1-octene hydrogenation

Cyclohexene is an aromatic compound containing unsaturated bond in the ring. Hydrogenation of olefins containing double bonds inside the aromatic ring is stronger than that of the other olefins containing double bonds outside the aromatic ring. As shown in Figure 0, the activity of the SiAPTES-ThioRh catalyst was very low at 350 and $360 \mathrm{~K}$. When the temperature was increased to $370 \mathrm{~K}$, the conversion increased sharply, and $99.5 \%$ cyclohexane conversion was obtained in $180 \mathrm{~min}$. It was concluded that the catalyst had high activity only at high temperatures. The results are presented in Table 3 .

Table 3. Cyclohexene hydrogenation with Si-APTES-ThioRh catalyst

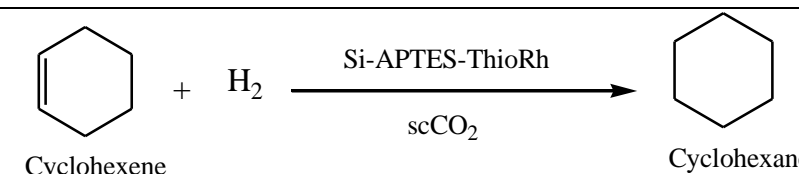

\begin{tabular}{ccccc}
\hline $\mathbf{T}(\mathbf{K})$ & $\mathbf{t}(\mathbf{m i n})$. & \%Cyclohexane & TON & TOF $\left(\mathbf{h}^{\mathbf{1}}\right)$ \\
\hline 350 & 360 & 7.7 & 130 & 22 \\
360 & 360 & 15.2 & 257 & 43 \\
370 & 180 & 99.5 & 1683 & 561 \\
\hline
\end{tabular}

$\mathrm{P}_{\mathrm{T}}=102$ bar, $\mathrm{P}_{\mathrm{H} 2}=10$ bar, $\mathrm{m}_{\text {cat }}=10 \mathrm{mg}, \mathrm{V}_{\text {subst }}: 100 \mu \mathrm{L}, \mathrm{n}_{\mathrm{s}} / \mathrm{n}_{\text {cat. }}=1691$ 


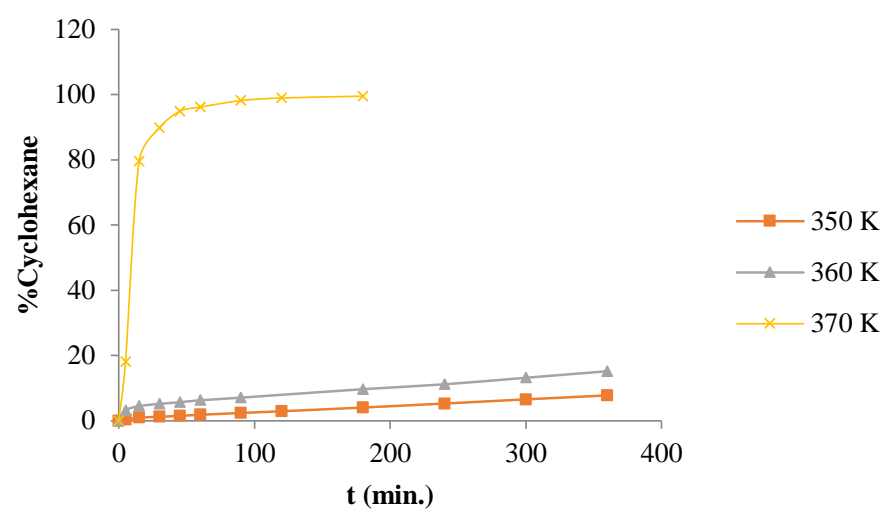

Figure 9. The effect of temperature on cyclohexene hydrogenation

The selectivity of the Si-APTES-ThioRh catalyst for the hydrogenation of aromatic and aliphatic alkenes was examined. Related experiments were carried out at $370 \mathrm{~K}, 10 \mathrm{bar}_{2}$ and a total pressure of 1500 psi. At the end of the 45-minute reaction as shown in Figure 10, the catalyst was found to have higher selectivity to styrene ( $52.7 \%$ ethyl benzene, $47.1 \%$ n-octane).

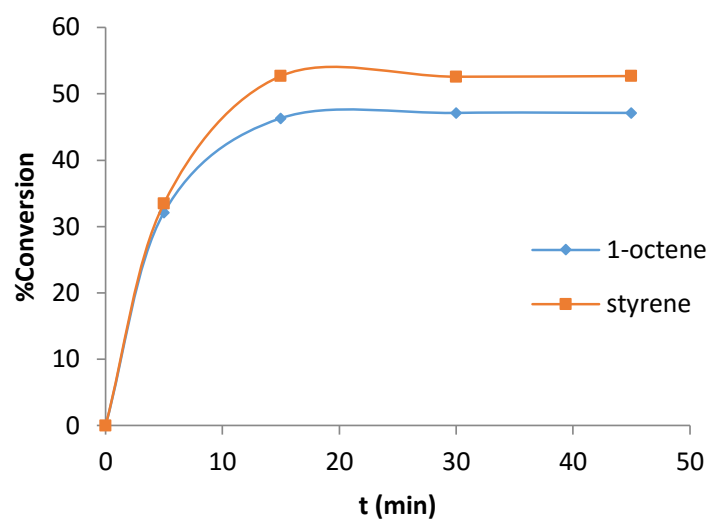

Figure 10. Selectivity of heterogenized catalyst $\left(\mathrm{T}=370 \mathrm{~K}, \mathrm{P}_{\mathrm{H} 2}=10 \mathrm{bar}, \mathrm{P}_{\mathrm{T}}=1500 \mathrm{psi}\right)$

The activities of the heterogenized catalyst and homogeneous catalyst in hydrogenation of alkenes were compared under same conditions. As shown in Table 4, the activity of the heterogenized catalyst is much higher than homogeneous catalyst in all olefins. The heterogenized catalyst showed very effectivity especially in the styrene and cyclohexene hydrogenation, while the homogeneous catalyst almost had no activity.

Table 4. Heterogenized catalyst versus to homogeneous ones

\begin{tabular}{|c|c|c|c|c|c|c|c|c|c|c|c|c|}
\hline \multirow[b]{2}{*}{ Type of Catalyst } & \multicolumn{4}{|c|}{ Styrene } & \multicolumn{4}{|c|}{ 1-Octene } & \multicolumn{4}{|c|}{ Cyclohexene } \\
\hline & $\mathrm{T}^{\mathrm{a}}$ & $\mathrm{t}^{\mathrm{b}}$ & $\%$ & TOF & $\mathrm{T}$ & $\mathrm{t}$ & $\%$ & TOF & $\mathrm{T}$ & $\mathrm{t}$ & $\%$ & TOF \\
\hline ThioRh & 350 & 360 & 4.8 & 2 & 350 & 60 & 89.0 & 184 & 370 & 360 & 0 & 0 \\
\hline Si-APTES-ThioRh & 350 & 60 & 99.6 & 991 & 350 & 180 & 99.7 & 366 & 370 & 180 & 99.5 & 561 \\
\hline
\end{tabular}

The solvent effect on catalytic hydrogenation reaction was also investigated. For this purpose, experiments were performed in $\mathrm{MetOH}$ and hegzan media under optimum reaction conditions. As shown in Table 5, the best conversions were obtained in $\mathrm{scCO}_{2}$ and $\mathrm{MetOH}$ in styrene and 1-octene hydrogenation. In cyclohexene hydrogenation, $\mathrm{scCO}_{2}$ is a more effective media for catalyst. Using $\mathrm{scCO}_{2}$ instead of organic solvents provide easier removing of solvent at the end of the reaction. Thus, the problem of contamination of products and catalysts is disappear. 
Table 5. Solvent effect on the activity of catalyst

\begin{tabular}{l|ccc|ccc|ccc}
\hline \multirow{2}{*}{ Solvent } & \multicolumn{4}{|c|}{ Styrene } & \multicolumn{3}{c|}{ 1-Octene } & \multicolumn{3}{c}{ Cyclohexene } \\
\cline { 2 - 9 } & $\mathrm{T}^{\mathrm{a}}$ & $\mathrm{t}(\mathrm{min})$ & Conv.(\%) & $\mathrm{T}$ & $\mathrm{t}(\min )$ & Conv.(\%) & $\mathrm{T}$ & $\mathrm{t}(\min )$ & Conv.(\%) \\
\hline $\mathrm{scCO}_{2}$ & 370 & 60 & 99.7 & 370 & 90 & 100 & 370 & 180 & 99.5 \\
$\mathrm{MetOH}$ & 370 & 30 & 100 & 370 & 60 & 100 & 370 & 180 & 88.5 \\
Hegzan & 370 & 120 & 84.0 & 370 & 90 & 88.5 & 370 & 180 & 21.8 \\
\hline
\end{tabular}

There are many studies in the literature investigating the activity of heterogeneous homogeneous catalysts in hydrogenation reactions. For example, Merckle et al reported the hydrogenation reaction of bromostyrene in organic solvent media (toluen or THF) by immobilized catalysts of the Wilkinson type [20]. Wilkinson's catalyst is the best known for catalyzing hydrogenation of olefin. They reported that bromoethylbenzene conversion is $100 \%$ in $300 \mathrm{~h}$. TOF value is not specified in this study. We have obtained $100 \%$ conversion in $0.75 \mathrm{~h}$ for styrene (structurally similar to bromostyrene). Lopez Castillo et al reported the hydrogenation of 1-octene and cyclohexene in $\mathrm{scCO}_{2}$ media by $\mathrm{Rh}$ catalyst supported with fluoroacrylate copolymer. They reported nearly $100 \%$ total conversion for 1 -octene and $51 \%$ maximum conversion for cyclohexene in $12 \mathrm{~h}$ [21]. If we compare the efficiency, our catalyst is more active in the hydrogenation of both hydrocarbons. We obtained $100 \%$ conversion for 1-octene in $1.5 \mathrm{~h}$ and 99.5 conversion for cyclohexene under $10 \mathrm{bar}_{2}$ pressure in $3 \mathrm{~h}$.

\section{CONCLUSION}

In this paper, we synthesized a new silica-supported perfluorinated thiophene rhodium (I) (Si-APTESThioRh) complex as heterogenized homogeneous catalyst. Both of the heterogenization of homogeneous catalyst and the catalytic experiments were performed in environment-friendly $\mathrm{scCO}_{2}$ media. The catalyst was found to be active in styrene, 1-octene and cyclohexene hydrogenation. It was found that the temperature affected the activity of the catalyst positively. More importantly, it can be reused without too much loss of its activity. Although the selectivity of heterogeneous catalysts is generally low, Si-APTES-ThioRh catalyst had quite a good selectivity. When the results obtained with heterogenized catalyst were compared with homogeneous form, the catalytic activity of the heterogenized catalyst was found to be high than homogeneous catalyst.

\section{ACKNOWLEDGEMENTS}

We thank to the Anadolu University Plant Drug and Scientific Research Center (AUBIBAM) for NMR measurements and also Anadolu University Commission of Scientific Research Projects for financial support (Project No. 1101F010).

\section{REFERENCES}

[1] Jingchang Z, Hongbin W, Hongtao L, Weiliang C. Hydroformylation of propylene in supercritical $\mathrm{CO}_{2}+\mathrm{H}_{2} \mathrm{O}$ and supercritical propylene $+\mathrm{H}_{2} \mathrm{O}$. Journal of Molecular Catalysis A: Chemical 2006; 260: 95-99.

[2] Subramanlam B and McHugh MA. Reactions in Supercritical Fluids-A Review. Ind Eng Chem Process Des Dev 1986; 25: 1-12.

[3] Baiker A. Supercritical Fluids in Heterogeneous Catalysis. Chem Rev 1999; 99: 453-473.

[4] Aymonier C, Loppinet-Serani A, Reveron H, Garrabos Y, Cansell Francois. Review of supercritical fluids in inorganic materials science. J of Supercritical Fluids 2006; 38: 242-251.

[5] Leitner W. Supercritical Carbon Dioxide as a Green Reaction Medium for Catalysis. Acc Chem Res 2002; 35: 746-756. 
[6] Wells S, DeSimone JM. $\mathrm{CO}_{2}$ Technology Platform: An Impor-tant Tool for Environmental Problem Solving. Angew Chem Int Ed 2001; 40: 519-527.

[7] Jessop PG, Leitner W. Chemical Synthesis Using Super-critical Fluids; New York, NY, USA: Wiley, 1999.

[8] Zosel K. Separation with Supercritical Gases: Practical Applications. Angew Chem Int Ed Engl 1978; 17: 702- 09 .

[9] Sellin MF, Cole-Hamilton DJ. Hydroformylation reactions in supercritical carbon dioxide using insoluble metal complexes. J Chem Soc Dalton Trans 2000; 1681-1683.

[10] Jessop PG, Ikariya T, Noyori R. Homogeneous Catalysis in Supercritical Fluids. Chem Rev 1999; 99: 475-493.

[11] Cole-Hamilton DJ. Homogeneous catalysis-new approaches to catalyst seperation, recovery, and recycling. Science 2003; 299: 1702-1706.

[12] Satterfield CN. Heterogeneous catalysis in practise. McGraw-Hill, New York, NY, USA, 1980.

[13] Kirschning A. Immobilized Catalysts: solid phases, 1mmobilization and application. Springer, Germany, 2004.

[14] Barbaro P, Liguori F. Heterogenized homogeneous catalysts for fine chemicals production: materials and processes. Springer, Firenze, Italy, 2010.

[15] Zois D, Vartzouma C, Deligiannakis Y, Hadjiliadis N, Casella L, Monzani E, Louloudi M. Active catalytic centers in silica-supported $\mathrm{Cu}$ (II) and $\mathrm{Mn}$ (II) biomimetic complexes: Correlation between catalytic and EPR data. Journal of Molecular Catalysis A: Chemical 2007; 261: 306-317.

[16] Opanasenko M, Štěpnička P and Čejka J. Heterogeneous Pd catalysts supported on silica matrices. RSC Adv 2014; 4: 65137-65162.

[17] Wan Y, Wan Y, Zhang F, Lu Y, Li H. Immobilization of Ru(II) complex on functionalized SBA15 and its catalytic performance in aqueous homoallylic alcohol isomerization. Journal of Molecular Catalysis A Chemical 2007; 267: 165-172.

[18] Yilmaz F, Mutlu A, Ünver H, Kurtça M, Kani İ. Hydrogenation of olefins catalyzed by Pd (II) complexes containing a perfluoroalkylated S-O chelating ligand in supercritical $\mathrm{CO}_{2}$ and organic solvents. Journal of Supercritical Fluids 2010; 54: 202-209.

[19] Ikuhara YH, Saito T, Takahashi S, Sasaki Y, Hirayama T. Synthesis and microstructural analysis of homogeneously dispersed nickel nanoparticles in amorphous silica. Journal of the American Ceramic Society 2012; 95: 524-529.

[20] Merckle C, Blumel J. Improved rhodium hydrogenation catalysts immobilized on silica. Topics in Catalysis 2005; 34: 5-15.

[21] Lopez Castillo Z, Flores R, Kani İ, Akgerman A, Fackler JP. Evaluation of Polymer Supported Rhodium Catalyst in 1-Octene Hydroformylation in Supercritical Carbondioxide. Ind. Eng. Chem. Res. 2003; 42: 3893- 3899 